\title{
Sense of Coherence in Persons with Dementia and Their Next of Kin- A Mixed-Method Study
}

\author{
Annika Kjallman Alm1, Per Hagglund², Norbergh Karl-Gustaf', Hellzen Ove ${ }^{1}$ \\ ${ }^{1}$ Department of Nursing, Mid Sweden University, Sundsvall, Sweden \\ ${ }^{2}$ Head of Support Centre, Harnosand Municipality, Harnosand, Sweden \\ Email: annika.kjallman@miun.se, per.hagglund@harnosand.se, karl-gustav.norbergh@miun.se, \\ ove.hellzen@miun.se
}

Received 23 April 2015; accepted 19 May 2015; published 22 May 2015

Copyright (C 2015 by authors and Scientific Research Publishing Inc.

This work is licensed under the Creative Commons Attribution International License (CC BY). http://creativecommons.org/licenses/by/4.0/

(c) (i) Open Access

\begin{abstract}
Indications of dementia disease include deterioration of memory, thinking, behaviour, and the ability to perform everyday activities. Any of these symptoms can lead to stress and difficulties organizing everyday life. As a way to view factors that support human health and well-being despite stressful situations, Antonovsky introduced a salutogenic model. This model proposes that sense of coherence primarily determines physical and mental health i.e. psychological well-being. Having a sense of coherence in everyday life can reduce the impact of stress on the individual in everyday life. The study's aim of this study was to explore how participants in existing support groups scored on the Sense of Coherence Scale (SOC), and what they perceived as contributory factors to a meaningful, manageable, and comprehensible everyday life in the presence of dementia using a mixed method. Persons with dementia had the highest scores on the SOC scale and their partners the lowest. Persons with dementia expressed that being with others who understood them made their everyday life comprehensible and manageable. Their partners expressed that learning about dementia was helpful in managing and comprehending everyday situations. The adult children expressed that it was meaningful to care for their parents and they scored slightly higher than the partners on the SOC scale. Long-term ongoing support supplemented with information and social support can contribute to the sense of coherence in persons with dementia and their next of kin.
\end{abstract}

\section{Keywords}

Dementia, Next of Kin, Nursing, Mixed Method, Sense of Coherence, Support Groups 


\section{Introduction}

Dementia disease leads to deterioration of memory, thinking, behaviour, and the ability to perform everyday activities. Dementia is one of the major causes of disability and dependency among older people worldwide with 7.7 million new cases every year. The progression of the disease is different for every person affected [1] [2]. Personality, biography, health status, and environment also have an impact on the development of the disease [3]. Recently stress has been shown as a risk factor for developing dementia [4] [5], and can also increase the risk for confusion or delirium in persons with dementia [6] [7].

On a practical everyday level, people with dementia may have problems with short-term memory such as keeping track of a purse or wallet, paying bills, planning and preparing meals, remembering appointments or travelling out of the neighbourhood [8]. Hedman, Hansebo, Ternestedt, Hellström and Norberg [9] found that people with dementia struggled to preserve their previous selves and to construct new selves incorporating new skills in managing life with dementia [9].

\section{Background}

Caring for a person with dementia poses special challenges. Dementia has physical, psychological, social, and economic repercussions on caregivers, families, and society [10]. In Sweden, Parliament passed a law in 2009 that states: "Municipalities are obliged to offer support to persons caring for people with chronic illnesses, elderly people, or people with functional disabilities” [11]. There are health risks for care-giving spouses stemming from stress-related symptoms such as depression, anxiety, and fatigue [12]-[15]. Seventy-four percent of caregivers of people with dementia reported that they were "somewhat concerned" to "very concerned" about maintaining their own health since becoming a caregiver [8]. Antonovsky introduced a salutogenic model as a way to view factors that support human health and well-being despite stressful situations. More specifically, the “salutogenic model” is concerned with the relationship between stress, coping, and health. Antonovsky's salutogenic model proposes that Sense of Coherence [16]-[18], primarily determines physical and mental health i.e. psychological well-being. Sense of Coherence is defined as a global orientation that expresses the extent to which one has a pervasive, enduring though dynamic feeling of confidence that one's internal and external environments are structured, predictable, and explicable (comprehensibility). Resources are available to meet the demands posed by these stimuli (manageability). Meaningfulness means that these demands are challenges worthy of investment and engagement ([16], p. 19). Self-reported anxiety and depression have been shown to be associated with low levels of sense of coherence [19]. Studies show that support to caregivers can alleviate stress and increase psychological well-being [20] [21]. So how do members in existing support groups in a municipality in Sweden rate their Sense of Coherence and what do they perceive as contributory factors for a meaningful, comprehensible, and manageable everyday life?

\section{Rationale for This Study}

The study aimed at explore how members of existing support groups score on the Sense of Coherence Scale and what they perceive as contributory factors to a meaningful, manageable, and comprehensible everyday life in the presence of dementia. The study is part of a larger project in which we interviewed couples about their experiences in long term ongoing existing support groups [22] as well as well as adult children of persons with dementia to find out what it means for them to have a parent with dementia [23].

\section{Methods}

\subsection{Design}

The study had a mixed method approach with both qualitative and quantitative parts exploring the participants' sense of coherence. The study was conducted after approval from the Ethics Committee of the Medical Faculty, Umea (Dnr 2011-93-31). Interviewing vulnerable people such as those with a dementia can cause emotional upset for the individual. Therefore, all interviews were conducted at the support centre with staff members on hand, who were familiar with the participant, and able to take care of any problematic situation if and when it occurred. 


\subsection{Participants}

The participants in the qualitative part consisted of four persons with dementia (PwD) and four healthy partners as well as nine adult children (for overview see Table 1(a)). The participants in the quantitative part consisted of twelve adult children, ten partners, and six persons with dementia $(\mathrm{PwD})$ who were part of a support group during the research period (for overview see Table 1(b)). The participants from the qualitative aspect of this study also filled in the SOC instrument as well as caregivers and adult children from support groups for dementia.

The participants were all approached at a support group meeting and informed about the study and what it entailed. Written information and consent forms were also distributed. Those who consented to participate in the study were included. All questionnaires were filled in anonymously at a support group meeting with a code for each group: 1 for PwD, 2 for partner, and 3 for adult children. There were no dropouts during this study. The questionnaires were then mailed free of charge to the researcher.

The study was conducted at a municipal support centre in northern Sweden among participants of an existing long-term ongoing support group. The support group is one of many held at the municipal support centre by trained social workers, who specialise in dementia care, and is structured by participants' levels of cognitive function and by content. The group receives information and education about dementia in a social context. All meetings are free of charge and held at the support centre facilitated by trained social workers. Meetings take place twice a month and usually last between 90 minutes and 2 hours, including a coffee break. The participants are a part of the group for as long as they like and can move to other groups according to need. Topics include brain function and factors that can influence function, dealing with memory loss, reminiscence, strategies to improve memory, and latest research regarding dementia. Facilitators always open meetings by reminding everyone that everything said in the group context is confidential. The municipality also offers next-of-kin groups, education, voluntary work, social meeting arenas as well as day care facilities to persons with dementia and their next of kin. Three staff members offer support services through the support centre. A unique cooperation between the local geriatric clinic and the support centre has led to a referral time of 4 - 6 weeks between being diagnosed and receiving support from the centre.

\subsection{Data Collection}

The qualitative data was collected through interviews from October to November 2011 and March to May 2012. Data consisted of material gathered from semi-structured interviews with the participants that was digitally recorded and transcribed [22] [23].

The quantitative data was collected in February 2012 using Antonovsky's Sense-of-Coherence Scale (SOC) [24]-[26] to measure sense of coherence, and the SOC questionnaire, which consists of 29 questions/propositions that can be answered using numbers from 1 - 7, with 1 signifying "do not agree" up to 7 which is "totally agree”. Possible sum scores ranged from 29 to 203, with higher scores indicating greater coherence. Scores

Table 1. Description of participants in quantitative part.

(a)

\begin{tabular}{cccc}
\hline Quantitative part & Group 1 PwD & Group 2 & Group 3 \\
\hline MMSE & $23-28$ & - & - \\
age & $73-78$ & $55-75$ & $32-62$ \\
& & & $\mathrm{M}=4$ \\
gender & $\mathrm{M}=3$ & $\mathrm{~F}=5$ & $\mathrm{~F}=10$ \\
\hline
\end{tabular}

(b)

\begin{tabular}{cccc}
\hline Qualitative part & Group 1 PwD & Group 2 & Group 3 \\
\hline MMSE & $23-28$ & - & - \\
age & $73-78$ & $55-75$ & 32 \\
gender & $\mathrm{M}=3$ & $\mathrm{M}=1$ & $\mathrm{M}=1$ \\
& $\mathrm{~F}=1$ & $\mathrm{~F}=3$ & $\mathrm{~F}=8$ \\
\hline
\end{tabular}


below 130 could indicate that the individual is in need of professional help. SOC's psychometric properties have been well-demonstrated in substantial previous research [24]-[27]. The SOC scale covers three main areas, namely: comprehensibility (11-items), manageability (10-items) and meaningfulness (8-items). Comprehensibility (the cognitive component) is the sense that one's internal and external environment is ordered, consistent, structured, and clear. Manageability (the instrumental component) is the sense that there are resources at one's disposal that are adequate to meet the demands of the stimuli. Meaningfulness (the motivational component) refers to those events that tend to be viewed as challenges worthy of emotional investment and commitment.

The question set-up varies from positive to negative statement with every other question. The instrument consisted of 29 items that examined the comprehensibility, manageability, and meaningfulness of the participants' lives. A sample item was “Do you have the feeling you don't really care about what is going on around you?" (Reverse coded). The items were coded on a seven-point scale, reflecting various levels of agreement. Items 1,4 , $5,6,7,11,13,14,16,20,23,25$, and 27 were reverse coded.

\section{Analysis}

The quantitative data were analysed with SPSS for Windows, version 21. Descriptive analysis, means, total score, and standard deviation (Std) were used. All questionnaires were filled in anonymously at a support group meeting with a code for each group: 1 for Persons with Dementia (PwD), 2 for partner, and 3 for adult children. The questionnaires were then mailed free of charge to the researcher.

The qualitative data consisted of semi-structured interviews with the participants that was digitally recorded and transcribed. The couples were first interviewed together; individual interviews with each took place one week later. Data from the adult children consisted of digitally recorded, open interviews with nine participants, eight females, and one male between the ages of 35 and 65 (in total 17 participants). The interviews were conducted at the support centre by the first author since it was most convenient for the participants (for overview of participants see Table $1(a)$ and Table $1(b))$.

The interviews were analysed in a deductive manner [28] using meaningfulness, comprehensibility, and manageability as categories to explore the data regarding sense of coherence in everyday life as a participant in a support group. The text was divided into meaning units regarding categories and then condensed (see Table 2). The condensed meaning units were then divided into subcategories under the main categories. To ensure rigor in data analysis, all authors were involved in the analysis. Then they met to compare notes and discuss their analyses until consensus was reached regarding the findings. The quantitative data collection was done in January 2012 and the interviews in autumn 2011 and spring 2012. However all the results are combined in this study to give a broader description of Sense of Coherence from the participant's.

\section{Findings}

The findings will be presented with a summary of the quantitative result and an overview of the result for each

Table 2. Examples of qualitative analysis.

\begin{tabular}{|c|c|c|c|}
\hline Meaning unit & Condensation & Subcategory & Category \\
\hline $\begin{array}{l}\text { Well, what should I say... it's all good... because it is } \\
\text { good to get out of the house and meet others... it feels } \\
\text { good }\end{array}$ & $\begin{array}{l}\text { It's good to get out of the house } \\
\text { and meet others }\end{array}$ & $\begin{array}{l}\text { To have social } \\
\text { connections }\end{array}$ & \multirow[t]{2}{*}{ Meaningfulness } \\
\hline $\begin{array}{l}\text { If I can share what I have felt and hear others share } \\
\text { their feelings then it feels much, much better }\end{array}$ & $\begin{array}{l}\text { It feels better to share feelings with } \\
\text { others }\end{array}$ & To have support & \\
\hline $\begin{array}{l}\text { But this group is invaluable, you get different } \\
\text { perspectives, that every case is so different, it's amazing! }\end{array}$ & $\begin{array}{l}\text { The group is invaluable because it } \\
\text { provides different perspectives }\end{array}$ & $\begin{array}{l}\text { To take part in a support } \\
\text { group }\end{array}$ & \multirow{3}{*}{ Comprehensibility } \\
\hline $\begin{array}{l}\text { I mean now I can distinguish between the person and } \\
\text { effects of the condition, that nature can put you through } \\
\text { this }\end{array}$ & $\begin{array}{l}\text { Now I am able to make a } \\
\text { distinction between person and the } \\
\text { condition }\end{array}$ & To understand dementia & \\
\hline $\begin{array}{l}\text { But that's why it's so important with dementia that you } \\
\text { get support and help early on how to manage }\end{array}$ & $\begin{array}{l}\text { It's important to get support and } \\
\text { help }\end{array}$ & $\begin{array}{l}\text { To feel support from } \\
\text { others }\end{array}$ & \\
\hline $\begin{array}{l}\text { Yeah, I know it can only go one way but some seem to do } \\
\text { damn well, they told me, and they come to have coffee } \\
\text { and just take their car and go... }\end{array}$ & $\begin{array}{l}\text { You know it will be worse but } \\
\text { some do ok, driving them here and } \\
\text { so on. }\end{array}$ & To normalise dementia & Manageability \\
\hline
\end{tabular}


group (see Table 3) The qualitative result will then be presented according to each category, which is consistent with the subsections of the SOC. The subcategories for Meaningfulness were to have social connections and to have support. In Comprehensibility the subcategories were to understand dementia and to take part in a support group. In Manageability the subcategories were to feel support from others and to normalise dementia.

\subsection{Quantitative Findings}

The mean total score for SOC in group 1 consisting of persons with dementia (PwD) was 158 out of 203 with partners in group 2 at 143 and adult children in group 3 at 144 of 203. The overall score for PwD is slightly higher than the other two groups as seen in Table 3. However there are differences in the subsections with lower scores for questions regarding meaningfulness for PwD and higher scores for manageability and comprehensibility in the group than the other two groups with adult children and partners. The adult children scored higher than the other two groups in the subsection with questions regarding meaningfulness.

\subsection{Qualitative Findings}

\subsubsection{Meaningfulness}

The category Meaningfulness was analysed using the definition by Antonovsky [16] that meaningfulness is the extent to which an individual believes that life makes sense emotionally and that one possesses the motivation and desire to cope with encountered stimuli. The findings in the qualitative analysis showed that to have social connections and to have support was identified as meaningful by all three groups. Persons with dementia looked forward to going to the support group and meeting others in a social context and described that connecting with individuals with the same problems was enjoyable. I forget easily but I have to say I find this interesting and I enjoy coming here and meeting others. Others mentioned how they looked forward to going to the support groups and really wanted to attend every meeting. Their partners looked forward to the meetings to get out of the house and meet others and share feelings about their concerns, knowing everyone was experiencing similar situations. It feels good to talk to the others about our situation; it makes me feel safe (to have support). The adult children felt that the relationship between the participants within the support group was important to them. It's good to be part of the support group. I've been coming 5 - 6 years now and hearing the others, giving advice makes me happy.

\subsubsection{Comprehensibility}

The category Comprehensibility is analysed from Antonovsky's [16] definition of comprehensibility—that it is

Table 3. Mean for the groups regarding score in subsections and total score as well as Std in sense of coherence scale. The sense of coherence scale's subquestions pertain to comprehensibility with a minimum of 11 points and a maximum of 77 points; manageability min 10 to max 70, and meaningfulness with a minimum of 8 points to maximum of 56 points. These were added up in each of the three subsections and the mean for each group is shown in the table below.

\begin{tabular}{|c|c|c|c|c|c|c|}
\hline SOC & $\begin{array}{c}\text { Group (n) } \\
\text { 1 = PwD } \\
2 \text { = Partners } \\
\text { 3 = Adult children }\end{array}$ & Mean & Mean total & Min total & Max total & Std. deviation \\
\hline Meaningfulness & $\begin{array}{c}1(6) \\
2(11) \\
3(14)\end{array}$ & $\begin{array}{l}43.66 \\
42.09 \\
46.28\end{array}$ & $44.29^{*}$ & $27.00^{*}$ & $55.00^{*}$ & $\begin{array}{l}4.22 \\
6.56 \\
6.11\end{array}$ \\
\hline Comprehensibility & $\begin{array}{c}1(6) \\
2(11) \\
2(14)\end{array}$ & $\begin{array}{l}58.33 \\
49.72 \\
51.14\end{array}$ & $52.03^{*}$ & $37.00^{*}$ & $68.00^{*}$ & $\begin{array}{l}7.00 \\
8.12 \\
8.38\end{array}$ \\
\hline Manageability & $\begin{array}{c}1(6) \\
2(11) \\
3(14)\end{array}$ & $\begin{array}{l}55.83 \\
51.54 \\
51.37\end{array}$ & $52.29^{*}$ & $30.00^{*}$ & $67.00^{*}$ & $\begin{array}{l}5.70 \\
8.58 \\
8.39\end{array}$ \\
\hline SOC & $\begin{array}{c}1(6) \\
2(11) \\
3(14)\end{array}$ & $\begin{array}{l}- \\
- \\
-\end{array}$ & $\begin{array}{l}158 \\
143 \\
144\end{array}$ & $\begin{array}{c}148 \\
98 \\
109\end{array}$ & $\begin{array}{l}170 \\
185 \\
181\end{array}$ & $\begin{array}{c}9.8 \\
20.40 \\
22.13\end{array}$ \\
\hline
\end{tabular}

\footnotetext{
*All groups.
} 
the extent to which an individual perceives life's challenges in a clear, ordered, and structured manner. An individual with strong comprehensibility will find logic in various external and internally encountered stimuli. The analysis showed that what made the everyday life with dementia comprehensible was the ability to understand the dementia disease or to be given tools to better understand how to care for a person with dementia. This was considered important both for the partners and adult children. It's just after taking part in the support group that we really got an explanation and understood dementia. One of the adult children said-You have learned through the years how to act and you can look back and understand how it's connected. Taking part in a support group and meeting others with the same condition or problems and being able to share feelings gave them a greater understanding of the complexity of the condition. To the persons with dementia understanding the dementia disease and how to manage everyday life was understood as making sure to get enough rest and refrain from stressing or overexerting oneself. Yeah, well my memory has been broken, I forget a lot. They also felt understood in the support group and that others did not understand.

\subsubsection{Manageability}

The category Manageability is analysed using the definition by Antonovsky [16] that an individual who perceives that the requisite resources to cope successfully with life's challenges are available and they will endure and not be overwhelmed. The findings in the qualitative analysis showed that to be able to feel support from others and to normalise the dementia disease made everyday life manageable for all three groups. The adult children also felt it was a relief to talk to others and not feel as though they are the only ones with a parent suffering from dementia but rather to feel support from others in the same situation. If I hear others going through the same thing [it] just makes it easier. The partners expressed that it was important to receive help and support early after diagnosis on how to manage everyday life with dementia. We laugh and cry together, sometimes you just have to see the funny side of things but it's hard. Others mentioned that having support gave them strength to carry on. Sometimes I feel like I just can't cope but I just take one day at a time. For the persons with dementia it felt good to receive support from others in the group and from the moderators of the group who made it possible for them to make the best of their situation. It's how it is, you just have to make the best of it.

\subsubsection{Integration of Quantitative and Qualitative Findings}

When using a mixed method it is common to present an integration of both quantitative and qualitative results before moving on to the discussion of the result as suggested by Creswell [29]. The findings from the quantitative and the qualitative data analysis generated a broader understanding for sense of coherence within the groups than only one set of data. According to Antonovsky [16] successfully coping with tension, stressors or both depends on an individual's SOC as a whole. So out of the three groups, according to the quantitative result and Antonovsky, the PwD group was coping with their situation better than the other two groups. However comparing the subsections in SOC showed that meaningfulness was low in PwD and high in adult children. The high score for PwD was instead generated by high scores in comprehensibility and manageability. They expressed it as their memory was broken and that they had to refrain from becoming stressed. The adult children found it meaningful to be part of the support group and help each other. The partners scored slightly lower than the adult children and PwD in meaningfulness and comprehensibility and expressed that it felt good to talk to others in the same situation, and that learning about dementia was helpful in dealing with everyday situations. This suggests that they were struggling more with the situation than both adult children and PwD.

\section{Discussion}

The aim of this study was to explore how participants in existing support groups score on the Sense-of-Coherence (SOC) questionnaire and what they perceive as contributory factors to a meaningful, manageable, and comprehensible everyday life in the presence of dementia. This descriptive study therefore highlights areas of importance in support to PwD and their next of kin.

According to a study on elderly individuals' subjective health by Schneider, Driesch, Kruse, Wachter, Nehen and Heuft [30] there is a significant positive correlation between subjective health assessment and SOC in the elderly. It could therefore be argued that the PwD with high scores in SOC also have a subjective good health despite the presence of dementia. The findings of the qualitative analysis showed that social support and knowledge (understanding) were mentioned by all participants as factors that enhanced the comprehensibility in eve- 
ryday life in the presence of dementia. Duggleby, Swindle, Peacock and Gosh [31] demonstrated that it helped caregivers to have support from family and friends as well as appropriate service and knowledge from professionals. Also important to help them cope and manage the situation was that the professionals provided empathy, understanding, and knowledge [31]. The ongoing long-term support groups seemed to prepare the next of kin and the sufferer for each step of the journey with dementia. The healthy partners express that they know that it is going to be worse and prepare for that scenario making the progression more manageable to increase their sense of coherence according to Antonovsky [16]. Romero [32] found that a program for PwD aimed to improve maintenance of a sense of self through meaningful activities, understanding of their illness, and how to manage it improved social behaviour and decreased depression. Researchers have also emphasised autobiographical memory as crucial in sustaining the selfhood of people with dementia [33] [34] arguing that when people with dementia cannot remember facts about themselves they have difficulties knowing who they are. A support group focusing on social interaction and reminiscence like the one provided by the municipality in this study could therefore enhance the sense of self as well as the sense of coherence for people with dementia.

According to Antonovsky [35] the emotional counterpart to comprehensibility is meaningfulness that shows as an emotional investment in life. In this study it was perceived as meaningful by all participants to have social connections with others in the same situation and to have support or give support to others in the group. In other words they were all committed to the activities they perceived as meaningful and were motivated to participate in shaping events [36]; in this case the content of the support group. Pinquart and Sörensen [37] show in their meta-analysis of interventions with dementia caregivers that the broadest effect was seen in the interventions that called for active participation [37]. A systematic review of interventions aimed at caregivers and persons with Alzheimer's and related dementia disorders showed that multicomponent interventions based on education and support of caregivers delayed institutionalisation using only modest amounts of resources [38].

The participants in all support groups have suggestions in a list of topics that can be covered during the meetings but they decide the topic of the specific meeting and the moderators comply. This enables the moderators to give information and support in the areas where it is most wanted and needed at the time. The sense of being in control of the content of the support group could provide the participants with a sense of meaning as suggested by Frankl [39]. However Frankl's [39] perception of meaning is an active choice on an individual level and Anontovsky's sense of coherence is more an internal force developed during childhood and adolescence [40]. This could be expressed as the successful or salutogenic completion of the different stages in the life cycle developing a strong SOC for positive mental health, which neutralises the barrage of stressful life events an individual encounters on a daily basis [34]-[41].

The findings in this mixed-method study provide a broader understanding than those of a quantitative or qualitative study alone would of what participants perceive as important to enhance the sense of coherence within the support group context. Support groups should be structured so that persons with dementia have as much social interaction as possible, thus enhancing the healthy aspects of their personality. The moderators should enhance the salutogenic perspective for participants, making the situation more meaningful, comprehensible, and manageable, which could reduce stress and anxiety as suggested by Orgeta and Sterzo [19]. Participants should be given an opportunity to talk and ask difficult questions of the moderators without their spouse present. In this way the next of kin is empowered to take care of their spouse, and the strategy also empowers the spouse with dementia; their value as a person is enforced.

The SOC scale is not designed to be divided into subsections but to give an overall score, and the higher the score the higher the sense of coherence. In a study by Hart, Hittner and Paras [42] the subscales were shown to have weak internal consistency and could not be interpreted clearly in their 13-item short form. Antonovsky [23] also stressed that the SOC scale should be used unidimensionally indicating a global concept. However in this study we wanted to bring the qualitative aspect of Sense of Coherence together with the questionnaire and therefore added analysis of interviews to the study. We divided the 29-item questionnaire into subsections to better clarify the connection to the qualitative content. Ideally the interviews and the SOC would have been connected on an individual level however the ethical approval for the quantitative study was limited to grouplevel presentation only because of consideration to the vulnerability of the persons with dementia. This is also a limitation in the study and something that weakens the quantitative part; however the addition of the qualitative portion adds an individual perspective in the quotations. Also further research is needed to verify the effects in a more statistically significant finding that could be generalized to a broader population of persons with dementia and their next of kin. Ideally control groups and support groups in different municipalities could be selected us- 
ing the same model of support. Also qualitative studies with interviews with PwD as well as next of kin combining quantitative methods to triangulate the research question could be used.

\section{Conclusion}

Support groups should be structured so that persons with dementia have as much social interaction as possible, thus enhancing the healthy aspects of their personality. The moderators of the support groups should enhance the salutogenic perspective for all group members, making everyday life with dementia more meaningful, comprehensible, and manageable, which could reduce stress and anxiety. The next of kin should be given an opportunity to talk and ask difficult questions of the moderators without their diseased spouse present. In this way the next of kin is empowered to take care of the spouse, and the strategy also empowers the spouse with dementia; their value as a person is enforced in social interaction with others.

\section{References}

[1] De Boer, M.E., Herthog, C.M., Dröes, R.-M., Riphagen, I.I., Jonker, C. and Eefsting, J.A. (2007) Suffering from Dementia—The Patient's Perspective: A Review of the Literature. International Psychogeriatrics, 19, 1021-1039. http://dx.doi.org/10.1017/S1041610207005765

[2] Mountain, G.A. (2006) Self-Management for People with Early Dementia: An Exploration of Concepts and Supporting Evidence. Dementia, 5, 429-446. http://dx.doi.org/10.1177/1471301206067117

[3] Kitwood, T. (1997) Dementia Reconsidered: The Person Comes First. Open University Press, Buckingham.

[4] Greenberg, M.S., Tanev, K., Marin, M.-F. and Pitman, R.K. (2014) Stress, PTSD, and Dementia. Alzheimer's \& Dementia, 10, 155-165. http://dx.doi.org/10.1016/j.jalz.2014.04.008

[5] Andel, R., Crowe, M., Hahn, E.A., Mortimer, J.A., Pedersen, N.L., Fratiglioni, L., Johansson, B. and Gatz, M. (2012) Work-Related Stress May Increase the Risk of Vascular Dementia. Journal of American Geriatric Society, 60, 60-67. http://dx.doi.org/10.1111/j.1532-5415.2011.03777.x

[6] Hölttä, E.H., Laurila, J.V., Laakkonen, M.L., Strandberg, T.E., Tilvis, R.S. and Pitkala, K.H. (2014) Precipitating Factors of Delirium: Stress Response to Multiple Triggers among Patients with and without Dementia. Experimental Gerontology, 59, 42-46. http://dx.doi.org/10.1016/j.exger.2014.04.014

[7] Inouye, S.K., Westendorp, R.G.J. and Saczynski, J.S. (2014) Delirium in Elderly People. Lancet, 383, 911-922. http://dx.doi.org/10.1016/S0140-6736(13)60688-1

[8] Alzheimers Association (2014) The 2014 Alzheimer's Association Women and Alzheimer's Poll. http://www.alz.org/downloads/facts_figures_2014.pdf

[9] Hedman, R., Hansebo, G., Ternestedt, B.M., Hellström, I. and Norberg, A. (2012) How People with Alzheimer’s Disease Express Their Sense of Self: Analysis Using Harrés Theory of Selfhood. Dementia, 12, 713-733. http://dx.doi.org/10.1177/1471301212444053

[10] WHO (2012) Dementia: A Public Health Priority. http://whqlibdoc.who.int/publications/2012/9789241564458_eng.pdf

[11] Swedish Social Services Act (2009) Law, 2009:549. (In Swedish) http://www.riksdagen.se/sv/DokumentLagar/Lagar/Svenskforfattningssamling/Socialtjanstlag-2001453_sfs-2001-453/? bet $=2001: 453$

[12] Donaldson, C., Tarrier, N. and Burns, A. (1998) Determinants of Carer Stress in Alzheimer's Disease. International Journal of Geriatric Psychiatry, 13, 248-256. http://dx.doi.org/10.1002/(SICI)1099-1166(199804)13:4<248::AID-GPS770>3.0.CO;2-0

[13] McConaghy, R. and Caltabiano, M.L. (2005) Caring for a Person with Dementia: Exploring Relationships between Perceived Burden, Depression, Coping and Well-Being. Nursing and Health Sciences, 7, 81-91. http://dx.doi.org/10.1111/j.1442-2018.2005.00213.x

[14] Sanders, S. (2005) Is the Glass Half Empty or Half Full? Social Work in Health Care, 40, 57-73. http://dx.doi.org/10.1300/J010v40n03 04

[15] Schoenmakers, B., Buntinx, F. and Depeleire, J. (2010) Factors Determining the Impact of Care-Giving on Caregivers of Elderly Patients with Dementia. A Systematic Literature Review. Maturitas, 66, 191-200. http://dx.doi.org/10.1016/j.maturitas.2010.02.009

[16] Antonovsky, A. (1979) Health, Stress, and Coping. Jossey-Bass Inc., San Francisco.

[17] Antonovsky, A. (1987) Unraveling the Mysteries of Health. Jossey-Bass Inc., San Francisco. 
[18] Becker, C.M., Glascoff, M.A. and Felts, M. (2010) Salutogenesis 30 Years Later: Where Do We Go from Here? International Electronic Journal of Health Education, 13, 25-32.

[19] Orgeta, V. and Sterzo, E.L. (2013) Sense of Coherence, Burden, and Affective Symptoms in Family Carers of People with Dementia. International Psychogeriatrics, 25, 973-980. http://dx.doi.org/10.1017/S1041610213000203

[20] Coen, R.F., Stanwick, G.R., O’Boyle, C.A. and Coakley, D. (1997) Behavior Disturbance and Other Predictors of Carer Burden in Alzheimer's Disease. International Journal of Geriatric Psychiatry, 12, 331-336. http://dx.doi.org/10.1002/(SICI)1099-1166(199703)12:3<331::AID-GPS495>3.0.CO;2-J

[21] Jegermalm, M. (2003) Direct and Indirect Support for Carers. Journal of Gerontological Social Work, 38, 67-84. http://dx.doi.org/10.1300/J083v38n04_07

[22] Kjallman Alm, A., Hellzen, O. and Norbergh, K.-G. (2013) Experiences of Long Term Ongoing Structured Support in Early Stage of Dementia-A Case Study. International Journal of Older People Nursing, 9, 289-297.

[23] Kjallman Alm, A., Norbergh, K.-G. and Hellzen, O. (2013) What It Means to Be an Adult Child of a Person with Dementia. International Journal of Qualitative Studies on Health and Well-Being, 8, 10.

[24] Antonovsky, A. (1993) The Structure and Properties of the Sense of Coherence Scale. Social Science \& Medicine, 36, 725-733. http://dx.doi.org/10.1016/0277-9536(93)90033-Z

[25] Eriksson, M. and Lindström, B. (2006) Antonovsky’s Sense of Coherence Scale and the Relation with Health: Systematic Review. Journal of Epidemiology \& Community Health, 60, 376-381. http://dx.doi.org/10.1136/jech.2005.041616

[26] Sarvimäki, A. and Stenbock-Hult, B. (2000) Quality of Life in Old Age Described as a Sense of Well-Being, Meaning and Value. Journal of Advanced Nursing, 32, 1025-1033. http://dx.doi.org/10.1046/j.1365-2648.2000.01568.x

[27] Schumacher, J., Wilz, G., Gulzelmann, T. and Brähler, E. (2000) Die Sense of Coherence Scale von AntonovskyTeststatistische Überprüfung in einer repräsenta-tiven Bevölkerungsstichprobe und Konstruktion einer Kurzskala. Psychotherapie Psychosomatik Medizinische Psychologie, 50, 472-482. (In German) http://dx.doi.org/10.1055/s-2000-9207

[28] Elo, S. and Kyngäs, H. (2008) The Qualitative Content Analysis Process. Journal of Advanced Nursing, 62, 107-115. http://dx.doi.org/10.1111/j.1365-2648.2007.04569.x

[29] Creswell, J. (2009) Research Design. Qualitative, Quantitative, and Mixed Methods Approaches. 3rd Edition, Sage, California.

[30] Schneider, G., Driesch, G., Kruse, A., Wachter, M., Nehen, H.-G. and Heuft, G. (2004) What Influences Self-Perception of Health in the Elderly? The Role of Objective Health Condition, Subjective Well-Being and Sense of Coherence. Archives of Gerontology and Geriatrics, 39, 227-237. http://dx.doi.org/10.1016/j.archger.2004.03.005

[31] Duggleby, W.D., Swindle, J., Peacock, S. and Gosh, S. (2011) A Mixed Method Study of Hope, Transitions and Quality of Life in Family Caregivers of Persons with Alzheimer's Disease. BMC Geriatrics, 11, 88. http://dx.doi.org/10.1186/1471-2318-11-88

[32] Romero, B. (2004) Selbsterhaltungstherapie: Konzept, klinische Praxis und bisherige Ergebnisse (Self-Maintenance Therapy: Concept, Clinical Implementation, and Outcomes). Zeitschrift für Gerontopsychologie \& Psychiatri, 17, 119134.

[33] Jetten, J., Haslam, C., Pugliese, C., Tonks, J. and Haslam, S.A. (2010) Declining Autobiographical Memory and the Loss of Identity: Effects on Well-Being. Journal of Clinical and Experimental Neuropsychology, 32, 408-416. http://dx.doi.org/10.1080/13803390903140603

[34] Massimi, M., Berry, E., Browne, G., Smyth, G., Watson, P. and Baecker, R.M. (2008) An Exploratory Case Study of the Impact of Ambient Biographical Displays on Identity in a Patient with Alzheimer's Disease. Neuropsychological Rehabilitation, 18, 742-765. http://dx.doi.org/10.1080/09602010802130924

[35] Antonovsky, A. (1984) The Sense of Coherence as a Determinant in Health. In: Matarazzo, J.D., Ed., Behavioral Health: A Handbook of Health Enhancement and Disease Prevention, John Wiley, New York, 114-129.

[36] Sullivan, G.C. (1993) Towards Clarification of Convergent Concepts: Sense of Coherence, Will to Meaning, Locus of Control, Learned Helplessness and Hardiness. Journal of Advanced Nursing, 11, 1772-1778. http://dx.doi.org/10.1046/j.1365-2648.1993.18111772.x

[37] Pinquart, M. and Sörensen, S. (2006) Helping Caregivers of Persons with Dementia: Which Interventions Work and How Large Are Their Effects? International Psychogeriatrics, 18, 577-595. http://dx.doi.org/10.1017/S1041610206003462

[38] Olazarán, J., Reisberg, B., Clare, L., Cruz, I., Pena-Casanova, J., del Ser, T., Woods, B., et al. (2010) Nonpharmacological Therapies in Alzheimer's Disease: A Systematic Review of Efficacy. Dementia and Geriatric Cognitive Disorders, 30, 161-178. http://dx.doi.org/10.1159/000316119 
[39] Frankl, V.E. (2006) Man’s Search for Meaning. Beacon Press, Boston.

[40] Antonovsky, H. and Sagy, S. (2001) The Development of a Sense of Coherence and Its Impact on Responses to Stress Situations. The Journal of Social Psychology, 126, 213-225.

[41] Erikson, H.E. (1997) The Life Cycle Completed. W. W. Norton \& Company Inc., New York.

[42] Hart, K.E., Hittner, J.B. and Paras, K.C. (1991) Sense of Coherence, Trait Anxiety and the Perceived Availability of Social Support. Journal of Research in Personality, 25, 137-245. http://dx.doi.org/10.1016/0092-6566(91)90010-N 